\title{
A partir de los movimientos de un pájaro... La «danza de la perdiz» en los rituales ganaderos de los Andes peruanos ${ }^{1}$
}

\author{
Juan Javier RiverA ANDÍA \\ Departamento de Antropología de América, Universidad de Bonn (Alemania) \\ jjriveraandia@gmail.com
}

Recibido: 10 de septiembre de 2011

Aceptado: 25 de octubre de 2011

\section{RESUMEN}

Este texto presenta un breve acercamiento a la visión que se tiene de un ave entre los pobladores de los Andes centrales del Perú. Exploramos esta perspectiva por medio de las representaciones colectivas que encontramos en un ritual y en las creencias y relatos sobre este animal en la sierra de Lima. De este modo, esperamos contribuir a saber un poco más acerca de qué papel juegan ciertos animales en los modos de pensar de raigambre amerindia en los Andes.

Palabras clave: Patrimonio inmaterial, Andes, aves, fauna, etnozoología, ritual, tradición oral.

\section{On the Movements of a Bird... The «Dance of the Partridge» in the Andean Cattle Branding Rituals}

\section{ABSTRACT}

This paper presents a brief look at the conception of a bird that the people of the central Andes of Peru have. We explore this perspective through the collective representations found in a ritual and in beliefs and stories about this animal in the mountains of Lima. In this way we hope to contribute to the knowledge about the role played by certain animals in the Andean ways of thinking of Amerindian roots.

Key words: Intangible patrimony, Andes, birds, fauna, ethnozoology, ritual, oral tradition.

Sumario: 1. Introducción. 2. El contexto de la «danza de las perdices»: la herranza. 3. El kiwyu: una expresión de la «contaminación de los comportamientos». 4. Consideraciones finales. Las perdices y los jóvenes. 5. Post-scriptum. 6. Referencias bibliográficas

\section{Introducción}

«Y allí hacían juramento solemne, a su usanza, por el sol: de sustentar la orden de caballería, y por la defensa del Cuzco morir, si necesario fuese. Y luego les abrían las orejas... En el comedio de esta plaza bailaban y hacían grandísimas fiestas a su modo, y andaban los que habían de ser caballeros cubiertos con las cabezas de leones, que tengo dicho: para dar a entender que serían valientes y fieros como lo son aquellos animales»

(Cieza de León 1985 [1871]).

\footnotetext{
1 Agradezco a la Fundación Alexander von Humboldt la beca posdoctoral que me ha permitido concluir éste y otros trabajos. Doy las gracias, además, a José Manuel Pedrosa, de la Universidad de Alcalá de Henares, y a Antoinette Molinié, Jean-Pierre Chaumeil y Gilles Tarabout de la Universidad de Nanterre (París X).
} 
Las perdices, a pesar del aprecio por su carne y sus huevos, y de la antigüedad de la crianza de animales en los Andes, parecen haberse mantenido fuera del dominio de las especies domesticadas en esta región. Así, por ejemplo, aparecen como un producto «crudo» en un texto del siglo XVI recogido por John Murra (1975), en el que se transcriben las categorías de productos de un quipu incaico usado para contar los tributos otorgados por las etnias bajo el control del $\mathrm{Cuzco}^{2}$. Ante todo, cabe notar que la inclusión de la perdiz entre estos tributos ilustra bien el aprecio que se le daba entre los variados recursos naturales de los Andes. En cualquier caso, el tributo de perdices no parece haber tenido «proporciones ni cuotas de energía» establecidas. De hecho, de haber sido criadas en vez de regularmente cazadas (como se recolectaban, por ejemplo, el pescado, las plumas, la madera, la caza, los huevos de patos silvestres, la miel y los camarones), sus cantidades habrían estado detalladamente fijadas (Murra 2002: 284).

En el estudio ya mencionado, Murra se pregunta por qué no hay mitos sobre las perdices y los otros productos crudos señalados en el quipu. Este artículo muestra, en primer lugar, que podemos encontrar, no solo mitos, sino también rituales o por lo menos datos en torno a uno de ellos. Ahora bien, en lo que respecta al modo en que es apropiado, las perdices se oponen, pues, a los animales domesticados en general, y al ganado en particular. Sin embargo, en cuanto al hábitat en que se encuentran, ambos, perdices y bestias domesticadas, coinciden. Esta obvia constatación bien podría servir de introducción al segundo objetivo de este trabajo: dar cuenta de la «danza de las perdices» que ciertos rituales ganaderos andinos incluyen en sus celebraciones. Esto es, comprender una cierta transformación de los hombres en aves durante las marcaciones del ganado. ¿Cuál es la relación entre la herranza y esta danza fundada sobre la atribución de «costumbres» a estas aves?

El punto de partida de nuestras intuiciones acerca de las representaciones de la perdiz en los rituales ganaderos, concuerda con los datos etnográficos recogidos por Gary Urton (1985) en torno a las definiciones de la madurez en Pacariqtambo (Cuzco, Perú). Urton indaga acerca de los cánones de la imaginación en torno a las analogías entre la fauna local y las características supuestamente típicas de los hombres en determinadas etapas de su ciclo vital. Así, ciertas formas de transformación social humana son conceptualmente asimiladas al dominio animal. Urton muestra que, de hecho, el mundo de los animales forma un telón de fondo sobre el cual los seres humanos formulan y reformulan continuamente sus ideas acerca de ellos mismos, de las características de sus formas de interacción social, y de sus historias personales y sociales (Urton 1985: 281).

Finalmente, en tercer lugar, nos gustaría sugerir aquí la necesidad de un estudio comparado del mundo de las metáforas relacionadas con los animales y los ciclos vitales en distintas regiones de los Andes. Queremos, por medio de este texto, contribuir al conocimiento de las características, las imágenes y los dilemas en torno a una de sus etapas: la juventud.

2 A saber: los seres humanos, los auquénidos, los tejidos de lana, los alimentos cultivados, los objetos confeccionados con fibra de cabuya, la cerámica, los vegetales no cultivados, la chicha, «toda fruta», sal blanca y pescado y, finalmente, las gallinas de Castilla, los huevos y las perdices. 


\section{El contexto de la «danza de las perdices»: la herranza ${ }^{3}$}

En contraste con los estudios sobre los ritos andinos en general, la bibliografía sobre los rituales en torno a los animales de crianza no es muy abundante. Estos ritos son, sin embargo, de muy amplia difusión e incluyen distintas especies: desde camélidos, vacunos y ovinos, hasta equinos y roedores. Estos últimos, por ejemplo, forman parte de rituales de curación en toda el área andina. Los ritos en torno al ganado equino apenas han sido descritos en Ayacucho (Gose 1994: 196) y el valle de Chancay (donde los asnos son, curiosamente, llamados «marianos») ${ }^{4}$. En lo que respecta a las ovejas, sus rituales -menos complejos que los otros-suelen estar asociados a los carnavales y al solsticio de invierno (Gose 1994: 194-224). Finalmente, los rituales que involucran auquénidos han sido descritos sobre todo en el sur de los Andes y con mayor frecuencia que las fiestas relacionadas con vacas y toros, quizá debido a que se los consideraba como menos «auténticos». Este último predominio temático tiene un correlato geográfico, especie de eco de un indigenismo que tomó las características sociales de los Andes del sur como un ejemplo paradigmático del «paisaje» rural del Perú. En consecuencia, los ritos observados en los Andes septentrionales y centrales del Perú han sido objeto de menor atención. Cabe notar que, aunque relativamente escasos, los estudios sobre los ritos ganaderos poseen una riqueza etnográfica que les otorga mucha vigencia. Sin embargo, no existe hasta el momento una definición general o una descripción de la estructura que subyace a las variantes andinas de la herranza. Esto se debe, probablemente, a la escasez de trabajos etnográficos.

Sea como fuere, aquí nos concentraremos sólo en una de las particularidades más enigmáticas de los ritos ganaderos andinos: sus alusiones a un animal que no es de crianza y que vive alejado de los hombres, aunque cercano al ganado y que mora en las alturas, a las perdices. El lugar donde primero hemos encontrado esta asociación es el valle de Chancay 5 .

Esbozaremos la estructura general de los ritos ganaderos en esta región, señalando sus partes constitutivas elementales ${ }^{6}$. Los ritos en torno a la identificación del ganado, además de las secuencias inicial y final, poseen, por decirlo así, un núcleo en el que se encuentran acciones que pueden dividirse, a su vez, en dos grupos. Cada

3 Las reflexiones que vienen a continuación se originan en nuestro trabajo de campo en la región entre los años 1999 y 2006. La etnografía de este periodo y área se ha publicado parcialmente (Rivera Andía 2003).

4 Los datos al respecto se encuentran en las fichas etnográficas inéditas de Alejandro Vivanco, incluidas en el archivo inédito reunido por «José María Arguedas» (y conservado en la Pontificia Universidad Católica del Perú). Dentro de este cuantioso material etnográfico se encuentran, además, numerosas fichas mecanografiadas con testimonios de profesores de escuelas rurales peruanas sobre las «costumbres» de los pueblos en que habitan. Nosotros hemos publicado un fragmento de las fichas de Vivanco (Rivera Andía 2003).

5 El valle de Chancay pertenece a la vertiente occidental de los Andes centrales del Perú. El río epónimo del valle se desliza hacia el mar desde las cumbres salpicadas de nieve, en un trayecto de apenas $122 \mathrm{~km}$, descendiendo alrededor de $4000 \mathrm{~m}$. La extensión de su cuenca, que determina los límites políticos de la actual provincia de Huaral, abarca unos $3.655 \mathrm{~km}^{2}$. Según los últimos datos censales, casi el 90\% de las familias de las comunidades más altas del valle practican la ganadería.

6 Es de notar, además, que los ritos de los Andes centrales (incluyendo los departamentos de Lima y Huánuco) parecen configurar un modelo más complejo que el de los ritos del sur andino. Los esquemas propuestos para los ritos de las comarcas del sur siguen las ideas y denominaciones que los participantes se hacen del ritual más que los hechos que éste incluye. 
grupo se caracteriza por un movimiento distinto. En el primero, las acciones tienden a establecer reuniones; en el segundo grupo, las acciones realizadas tienden a introducir separaciones. Ambos grupos obedecen, pues, a movimientos contrarios: uno de unión y el otro de división. Como dijimos, estos dos grupos nucleares de acciones, se encuentran rodeados por otras dos secuencias rituales, primero, por la secuencia que prepara el escenario de los acontecimientos, luego por la secuencia que marca el colofón del ritual y el retorno a la vida cotidiana. Las secuencias inicial y final, a manera de una obertura y de un corolario, rodean y completan las secuencias de conjunción y disyunción que dan vida al ritual.

Siguiendo esta estructura, el ritual ganadero constituye un comentario acerca del mundo animal. Ahora bien, este comentario parte de un cierto punto de vista acerca del espacio en que habita el ganado, las «alturas», concebido en los siguientes términos:

- Como un espacio foráneo y peligroso, definido por contraposición al pueblo donde moran los hombres y donde predomina la agricultura. Su otro nombre, pampa, remite a la carencia de contrastes y la ausencia de hitos orientadores. Su carácter peligroso se expresa en las entidades amenazadoras o marcadas por características anti-humanas que habitan «las alturas».

- Como un recurso imprescindible. Todas las villas andinas requieren de este mundo indistinto, silvestre e infecundo para sustentar su ganado, cuya importancia es fundamental para la reproducción y el desarrollo de las familias.

Las «alturas» constituyen, pues, al mismo tiempo, una fuente de subsistencia y un lugar que concentra diversas expresiones de la alteridad. Para conservar esta fuente de subsistencia, la herranza requiere confrontar el poder de las «alturas», lo que equivale a «volver a domesticar» el ganado. El ganado es «re-domesticado» tratándolo como un ser humano, enfatizando sus afinidades con el hombre, alejándolo de la influencia de los espíritus de los cerros y de las «alturas». Sucede, pues, que aunque por un lado el ganado -como animal domesticado- pertenece al mundo de los hombres, por el otro, requiere para sobrevivir los recursos de las «alturas». La herranza trata de resolver cada año esta contradicción. Intenta reafirmar el predominio de los hombres sobre estas bestias manteniendo, simultáneamente, buenas relaciones con los espíritus de los cerros (dueños de los recursos naturales de las «alturas»): se les arrebata el ganado y se les hace ofrendas. Este proceso es ilustrado por las secuencias de conjunción y separación de la herranza, señaladas más arriba.

Resumiendo, los ritos ganaderos implican una distinción, más o menos imaginaria, entre dos espacios: el pueblo (asociado a lo contrastado, lo cultivado y lo fértil) y las «alturas» (asociado a lo indistinto, lo silvestre y lo infecundo). La herranza traslada los rebaños de un espacio al otro, y lo hace, además, en un periodo del año en que se corre el riesgo de ser agredido por «la tierra». Los actores en juego son la comunidad campesina, los espíritus de los cerros y el ganado. En este marco se inscriben una serie de animalizaciones y humanizaciones sucesivas, un intercambio de papeles entre animales y hombres. Reuniremos a continuación los retazos que hemos hallado de una de sus expresiones más singulares: la «danza de las perdices». 


\section{El kiwyu: una expresión de la «contaminación de los comportamientos»}

A continuación daremos cuenta, primero, de las creencias en torno a la perdiz en los Andes y, luego, de las prácticas rituales que, en el contexto de la herranza, fundan estas creencias.

\subsection{Una perdiz que baila}

Los habitantes del valle de Chancay y de otras regiones llaman kiwyu a las perdices, a las que casi todos afirman haber visto alguna vez. En sus descripciones comparan el tamaño del kiwyu con el de una gaviota o una gallina. Algunos dicen que tiene poco más de diez centímetros de alto y el pico negro. Para unos es de color gris y para otros verde oscuro. En cualquier caso, todos afirman que su color las vuelve difícilmente distinguibles de los pastizales de las alturas en los que mora.

Algunos letrados del valle del Chancay aseguran que «francolina» es el nombre castellano del kiwyu (que, para algunos, era además el nombre «correcto»). En este caso, se alude posiblemente al francolín (Francolinus francolinus), un ave gallinácea parecida a la perdiz, de plumaje predominantemente negro y espalda gris. En su etnografía de una comunidad cercana a Pacaraos, Benavides Estrada (s/f) brinda una descripción un poco más detallada de su apariencia:

«es la perdiz de mayor tamaño que existe en el Perú. Habita en las altas punas. Su color es grisáceo, con finas rayas y manchitas amarillentas, vientre castaño, cabeza y cuello con rayas longitudinales en negro y blanco. Su nombre vulgar no es sino la onomatopeya de su grito de huida: «kiuy, kiuy, kiuy...». Sus huevos son de colores amarillentos y brillantes».

Por su parte, el Tinamotis Petlandii es un ave que pertenece al orden de las tinamiformes, y que habita en los pastizales y en las quebradas arbustivas de la puna (esto es, siempre por encima de los $3.500 \mathrm{~m}$ ). A esta especie no se le reconoce ninguna variedad geográfica lo suficientemente específica como para ser reconocida subespecie. Su distribución abarca el norte de Argentina, el norte de Chile (entre Tarapacá y Atacama), el occidente de Bolivia y el sur de Perú (quizá hasta Junín y Lima, escenario de nuestro trabajo de campo). Se trata, como lo señalaba el autor mencionado, de la perdiz sudamericana de mayor tamaño de la región andina. Tiene una longitud de unos $41 \mathrm{~cm}$, posee rayas negras y blancas en la cabeza y un color castaño en el vientre. Como todas las perdices sudamericanas (o tinamúes), su plumaje se mimetiza muy bien con su medio, por lo que es difícil distinguirla mientras no levante vuelo. Los nombres más comunes de esta ave son «keu», «kiula» y «pisaca» en Chile; «kuli», «kiwa», «quello», «francolina»y «yutu» en Perú

7 No he logrado definir la denominación científica de esta ave, aunque es posible que se trate de un animal similar -si no el mismo- al que llaman qewlla en el departamento de Ancash, y que es identificado como Larus serranus (Parker et al. 1976). Tschudi (1849: 223) consigna la misma clasificación que Parker. En el departamento de Cajamarca, existe un ave llamada qewilla, de color blanco (Quesada 1976). También en la región de Junín hay un ave de nombre similar: qiwlla o tiwlla (Cerrón-Palomino 1976). Benavides Estrada clasifica la «perdiz Kiula» del valle del Chancay como «Tinamotis petlandii» (s/f: 76). Se discute la similitud 
Lo que queremos añadir ahora a las descripciones sobre las características de esta ave es lo que los habitantes afirman de su conducta.

Es en el valle de Chancay donde recogí mis primeras noticias del peculiar comportamiento de este ave. Se cree que los kiwyu habitan, en grupos de siete u ocho, cerca de las lagunas más altas de la comarca pues «les gusta el agua». El viajero Tschudi confirma esta asociación cuando escribe: «On the lagunas swim large flocks of Quiullas (Larus serranus, Tsch.)» (Tschudi 1849: 223). Un topónimo de la sierra de Lima refuerza la asociación del kiwyu con los ambientes húmedos de la puna. En las tierras altas de Laraos (provincia de Huarochirí, departamento de Lima), existe una laguna llamada Quiulacocha, donde se celebran parte de los rituales en torno a los canales de agua de la comunidad (Vargas 1990: 102, 197). Recuérdese que «quiula» es otro de los nombres dados a esta perdiz en el valle de Chancay (Benavides s/f: 76).

Por su parte, Adelaar (1982: 41) recoge en el valle del Chancay el término kiwyu, que traduce no sólo como perdiz, sino también como «un baile tradicional». Kiwyuktáp qachwarinmi ulqukuna significa «los hombres bailan kiwyu»; y kiwyurishaq es traducido como «bailaremos kiwyu» (ibid.).

Muchos afirman, directamente, que el kiwyu se «familiariza» con sus toros y vacas. Se dice que cualquiera que camine por los pastizales de las alturas, sobre todo si pasa cerca de los lugares donde abreva el ganado, puede encontrarse con un grupo de kiwyu. Entonces, probablemente, el caminante pueda observar el «baile» que ejecutan las perdices. En efecto, las perdices bailan en un orden y una época del año determinados. Se dice, además, que la conformación de su baile distingue géneros y jerarquías: el macho manda, las hembras obedecen. Esta conducta «social» resulta de interés si recordamos que las perdices habitan un espacio asociado a lo silvestre: las «alturas».

Mis interlocutores gustaban de describir esta comparsa de animales, suerte de ritual celebrado por los kiwyus:

«Cantan una hora, por lo menos. Hay cantidad en los cerros. Sus huevos son como los del pavo. El huevo y el kiwyu son de color verde gris. Usted va para su lado y no lo encuentra. Andan en manchitas [grupos]. En un cerrito, en una pampa, empiezan a cantar. Forman un círculo y en el medio va el macho. Después que terminan, unos a los otros, se suben. Las hembras se tiran sobre el macho. De ahí han sacado el baile. Es la churreada. Bailan abriendo las alas».

Estas aves bailan y cantan especialmente en los meses en que se inicia la lluvia-lo que refuerza la idea anterior de que estas aves «gustan del agua»-. En su comparsa, las aves forman, pues, un círculo. En el centro de éste se coloca una de ellas. Para algunos de mis interlocutores, esta posición es ocupada siempre por un ave macho. Se dice, además, que los kiwyus «siguen las órdenes del que está en el centro», que éste es una especie de líder. Es el macho quien «manda» y quien dirige los movimientos de todas las demás. Con tal disposición, las aves comienzan a moverse en el mismo sentido, haciendo girar el círculo, y levantando una de sus patas. Así, las aves ejecu-

de estas aves con las gallináceas en general (aparentemente, son aves de condiciones zoológicas distintas, y deberían ser clasificadas como parientes de los ñandúes). La perdiz de los Andes, junto con la rama de este grupo en América del Sur (rheiformes) y con los pingüinos (sphenisciformes), formarían los tres órdenes de paleognathae, las aves ancestrales propias de América. 
tan el baile «sólo con un pie», dando algunos pasos tanto hacia adelante como hacia atrás. Cuando este baile va a terminar, cada una de las aves se lanza sobre la que tiene adelante y busca picotearla emitiendo un trino especial: «¡Churr! ¡Churr! ¡Churr!». Se cree que este sonido es el signo de que «se están pisando» [copulando]. Una vez que han terminado, se desploman. Entonces permanecen así, como si estuviesen «ebrios» o «muertos», durante varios minutos. En ese momento, se dice, es muy fácil atraparlas. Pero si nadie las perturba, luego despertarán y continuarán su baile. Algunos testimonios establecen, además, una suerte de diálogo contrastado entre las perdices hembras y machos:

«Son un macho y tres hembras. El macho va adelante y dice: «iKeuruu! ¡Keuruu! ¡Keurú!». Los otros dicen: «¡Kiurú-kiurú! ¡Kiurú-kiurú! ¡Kiurú-kiurú!» Y dan la vuelta alrededor de la roca. Después de cantar, se tiran sobre el suelo ¡Pum! Se cansan. Nuevamente, cuando suben, caminan en zigzag. El macho canta fuerte. La hembra canta menudito. Ambos cantan como si estuvieran haciendo una canción».

Los habitantes de las tierras altas del valle de Chancay tienen, pues, sus propias interpretaciones de este comportamiento animal. Los kiwyus tendrían tres motivaciones distintas - pero no necesariamente excluyentes- para bailar:

- La muerte próxima de una de las aves. En esta interpretación, la danza sería, pues, un suerte de rito fúnebre anticipatorio, una suerte de despedida asociada a la muerte.

- El apareamiento de las aves. En este tipo de explicación, los kiwyus estarían ejecutando un rito de emparejamiento, una suerte de matrimonio. En fuerte contraste con la interpretación anterior, aquí estaríamos, pues, casi frente a su inversión.

- Un cambio ambiental. Los comentarios de este tipo consideran la danza como un producto de la percepción, entre las aves, de un cambio en el clima. Los que se inclinan por esta interpretación, añaden que se trata de un cambio que representa «una alegría».

La tercera interpretación que asocia la danza a una transformación del medioambiente quizá sea la más fácil de abordar. Parece más o menos evidente que el «cambio» del que hablan (sin especificar siempre de cuál se trata) podría relacionarse con el próximo advenimiento de las lluvias. Es precisamente durante el fin de la sequía cuando danzan los jóvenes que las imitan ${ }^{8}$.

Las otras dos interpretaciones aluden, como ya señalamos, a procesos contrastados entre sí: el advenimiento de la muerte y el apareamiento. Uno está marcado por la próxima anulación de la vida, el otro tiene como consecuencia el nacimiento de una nueva vida. Agonía y copulación hablan, sin embargo, de algo común: una transposición brusca. Ambos estados anuncian un cambio radical entre dos estados opuestos: la vida y la muerte.

Recordemos que las referencias al clima aluden también a un cambio notable, entre dos estaciones, la de lluvias y la seca. Así, podemos considerar lo que tienen de

8 En el valle de Chancay y otras regiones andinas, las herranzas se concentran en torno a la época en que después de los meses de sequía, se espera el advenimiento de las lluvias. Estas lluvias fertilizan los pastizales y gracias a ello, los rebaños pueden acercarse un poco más al pueblo, pues el pasto dejará de estar restringido a las zonas más altas. En este sentido, las lluvias permiten un acercamiento del ganadero y sus animales. En este contexto, la asociación entre las perdices y las lluvias remite al papel de las precipitaciones dentro de la mitología sudamericana donde median entre el cielo y la tierra (finalmente alejados, luego de una cercanía excesiva para el nacimiento de la vida). 
común las tres interpretaciones. Todas aluden a una transformación radical, en dos ámbitos: el de la naturaleza ${ }^{9}$-de la estación seca a la lluviosa- y el de los animales ${ }^{10}$ - de la agonía a la cópula-.

Este recurso a las transiciones en estas interpretaciones de la danza de los kiwyus concuerda con ciertos aspectos fundamentales del ritual ganadero. Como se ha mostrado, el objetivo central de los rituales ganaderos es trasladar los rebaños desde un espacio a otro. Este movimiento implica atravesar una frontera casi metafísica entre dos espacios fuertemente contrastados; el paso de la pampa al pueblo está asociado a un cambio radical en el ganado: deja así de estar bajo la influencia de los espíritus de los cerros y entra en el ámbito de lo civilizado. Cambios radicales, estados contrastados, alteraciones de naturaleza, son las alusiones comunes que parecen compartir los rituales ganaderos, en general, y la danza de las perdices, en particular.

Esta danza que se atribuye a las perdices es «imitada» por los hombres. En 1963, Ortiz Rescaniere vio cómo esta danza era practicada por los padres de los narradores con los que yo conversé. Entonces, los jóvenes descendían de las alturas con el ganado gritando «ikiwyu! ¡kiwyu!» y gustaban, además, revolcarse en el suelo y levantar polvareda (lo que es relativamente sencillo, pues la tierra en el mes de agosto se encuentra muy seca). Las mozas, espantadas, veían luego cómo los muchachos tendidos en el suelo levantaban los pies en el aire y los agitaban dando vueltas sobre su espalda. Aún hoy, se pueden encontrar los ecos de este baile:

«Hay unas aves que son las francolinas, y esa francolina es el kiwyu. Cuando los escuchas, bailan en el campo. ¡Bailan! Hacen su «ruedo» [baile realizado en la herranza del ganado]. En un grupo de diez, de doce, de ocho. Entonces, hay un jefe que ordena a esas aves. Cuando ya se caen, ahí los puedes atrapar. Se quedan como borrachos. Por tradición, la comunidad, mis antecesores, han sacado una danza igual a la de los kiwyus. Son unas aves que andan en manada. Cuando llega la hora de bailar, toditos se reúnen. Hacen un círculo. Ellos mismos cantan. ¡Toditos bailan! Cuando hay nevada, vuela para abajo. Bailan en grupo hasta que se cansan. Tanto que bailan, se marean y quedan como borrachos. Se lanzan y dicen '¡Churr!'. Ahora los jóvenes del pueblo ya no saben bailar. La nueva era no sabe ni atar ni desatar. Hombres y mujeres, bailan».

Este apareamiento se representa cuando, al final de la «danza de las perdices», todos se lanzan intempestivamente unos sobre otros. Muchos cuentan que, en una ocasión, cuando una «gringa» (es decir, una persona «de piel blanca»o «de ojos claros») se lanzó sobre un varón, la gente comentaba riendo que en adelante los hijos de ese hombre también nacerían «gringos».

9 Puede ser útil hacerse algunas preguntas aquí. ¿Cuál es el concepto de «naturaleza» de los pobladores de raigambre amerindia en los Andes? ¿Hay alguna noción similar en alguna de las lenguas amerindias del área andina? ¿En qué contextos y con qué propósitos se usa? ¿Cuáles son los matices que distinguen a este concepto en el Mundo Andino? ¿De qué manera, pues, deberíamos comentar y hacer más comprensibles estas creencias e historias?

10 Es importante notar, como Adelaar (2007) lo señala, que no se conoce ningún concepto en quechua que sea traducible por «animal». En la región específica se usa también el concepto en castellano. 


\subsection{Imitar el comportamiento imaginado de los animales}

Casi no hay descripciones de una danza parecida fuera del valle de Chancay. Sus pobladores afirman que solamente algunos pueblos del valle ${ }^{11}$ ejecutan el baile del kiwyu. Fuera de los límites de la provincia de Huaral existen noticias de un baile parecido en tres regiones del Perú. Dos de ellas son provincias relativamente cercanas a la cuenca del río Chancay: Tarma (al este, en el departamento de Junín) y Canta (al sur, también en el departamento de Lima). La otra descripción proviene de un lugar inquietantemente lejano: la provincia de Carabaya, en el departamento de Puno; es decir, a miles de kilómetros al sur de Lima.

La noticia que se tiene sobre la danza en Tarma es muy escueta, pues no existe ninguna etnografía al respecto. Un «almanaque festivo», publicado con fines turísticos, sobre las fiestas del departamento de Junín (Baldeón 2001), menciona una fiesta llamada «Quiulla Danza». Según este documento, la celebración es el 24 de diciembre en una villa de la provincia de Tarma llamada San Pedro de Cajas.

El segundo lugar donde encontramos una «danza de las perdices» es Huaros (en la provincia de Canta, sierra de Lima). El contexto aquí no es, sin embargo, la herranza, sino su contrapartida en tanto ritual de ciclo económico: la limpieza ritual de los canales de riego. Además de nuestra propia observación ${ }^{12}$, realizada el año 2002 , tenemos otras dos breves fuentes para acercarnos a esta variante de la conducta ritual de las perdices: el ya mencionado archivo «Arguedas» de la PUCP y una descripción más reciente hecha por un lugareño (Santos 1999). En el primero, encontramos el testimonio de un profesor anónimo que observó la «limpia de acequia de los antepasados» en Huaros. Aquí transcribimos la parte de este ritual en la que entran en escena las perdices o «quibios»:

«Baile tradicional de los Parianes y los Quibios en el mes de noviembre...// La plaza sin obstáculo, dos hombres ingresan con su túnica de jerga y en sus sombreros de pajas en forma de triángulo; son los Quibios (representan las francolinas aves de nuestras alturas, que bailan dando vueltas hasta cansarse y luego quedan tendidas en el suelo y se le llama quibios por el tono de sus cantos; quibín... quibín... quibín). (Archivo «José María Arguedas». Fichas mecanografiadas sobre la provincia de Canta. Legajo: 47-48 [184]).

En primer lugar, notemos que, como en el valle de Chancay, son los varones los que personifican a la perdiz. Aquí aparecen junto con el «parián», protagonista usual de las celebraciones en torno de la limpieza de acequias. Con todo, sus significaciones merecen un estudio aparte que se ha emprendido parcialmente (Borea 2004; Rivera Andía 2002).

11 La danza de las perdices en el valle del Chancay parece estar restringida, pues, a unas cuantas comunidades agrupadas en su extremo oriental. He encontrado la danza en Pacaraos, Vichaycocha, Collpa y Viscas. En esta última comunidad es donde he hallado una versión más desarrollada de la danza, y donde he podido recopilar un mayor número de recuerdos y testimonios. Según los cuadernos de campo de Vivanco, que visitó la región en 1963, los mozos solían bailar como perdices en todos los pueblos de esta parte alta del valle.

12 Esta parte del trabajo de campo fue hecho junto con Patricia Fernández (Universidad de Barcelona), a quien aprovecho para agradecer su apoyo. 
Los kiwyus del valle de Canta llevan una «túnica de jerga» y un «sombrero de paja». En el valle de Chancay, hasta hace algunos años, los jóvenes que bailaban como kiwyus usaban ropas viejas, de jerga o de telas usadas como paño de limpieza. La palabra «túnica» refuerza, en la forma, la idea de ropa hecha de materiales sencillos y sin elaboraciones. Si se le suma a esto el rústico sombrero de paja, se obtiene una suerte de retrato estereotipado del «pastor» o, como se le llama en la región, «llacuaco».

A continuación, el profesor anónimo de las fichas etnográficas también alude a la conducta de apareamiento de las perdices. Añade:

«el uno es el macho y lleva una jeringa llena de chicha, para defenderse; su compañera la hembra; bailan imitando a las francolinas, con esta expresión quibiú... quibiú... quibiú y sus demostraciones amorosas diciendo currutututu... tu... tu... tu. (Archivo «José María Arguedas». Fichas mecanografiadas sobre la provincia de Canta. Legajo: 47-48 [184]).

Las perdices son, pues, representadas en pareja, aunque ambas sean personificadas por varones ${ }^{13}$. Más aún, no sólo aparecen en pareja, sino que, además, se imita el juego amoroso de las perdices, por medio de su gorjeo («quibiú, quibiú, quibiú... currutututu... tu... tu... tu...»). Los siguientes actos observados en Huaros son de más difícil interpretación. En efecto, otros personajes se unen a las perdices:

«en este instante entran los perros, representados por dos hombres, sus caras pintadas, sujetos por fuertes cadenas, amarrados de sus cinturas, conducidos por sus dueños elegantemente vestidos denominándose «Caballeros»... La misión de éstos [los perros] es que al menor disgusto de los quibios se lancen a matarlos; cada vez que los quibios son acosados, el macho se defiende con la jeringa, lanzando el líquido a la cara de los perros; estos esperan una señal; suena el disparo del cazador, cogen a sus presas y le dan muerte con tremendos sacudones. Conducen el cuerpo de los quibios a una mesa, hacen la apariencia de cortarles la cabeza; acercándose un viejito con una olla adornada de flores, llena ésta con chicha morada y brindan todos por la salud y felicidad del pueblo y el término de la fiesta. (Archivo «José María Arguedas». Fichas mecanografiadas sobre la provincia de Canta. Legajo: 47-48 [184]).

Sería difícil interpretar aquí esta suerte de escena de caza entre caballeros, canes y perdices. Mientras el cazador no dispare su arma, las perdices aun pueden defenderse de los perros utilizando una extraña jeringa llena de cerveza de maíz (llamada «chicha»). Una vez muertas por las fieras, se cortan las cabezas de las perdices y todos beben su «sangre» (también cerveza de maíz, pero teñida de rojo). La sucesión de los hechos hace pensar en una comunión y -por la decapitación sobre una mesa- en una especie de sacrificio, quizá vinculado a los espíritus de los cerros ${ }^{14}$.

13 Esta personificación de una pareja de ambos sexos por medio de dos varones es común en otras fiestas andinas. Así, por ejemplo, los «parianes» (hombres-zorros macho y hembra) siempre son representados por dos mozos. En un testimonio recogido en el valle de Chancay se alude también al apareamiento: «Entonces los viejos tenían que nombrar dos varones, uno se sorteaba para hembra y otro para macho. El que ganaba brincaba entre los dos compañeros y era macho. El que brinca es el macho, la hembra es el que aguanta el macho» (Borea 2004).

14 Aun más enigmático, quizá, resulta el anciano que porta un recipiente enflorado donde recoge la sangre de las perdices. En los ritos en torno a la limpieza de canales de riego que observé el año 2002, en el mismo 
Obtuvimos la tercera referencia a una danza de hombres-perdices gracias a una breve, pero densa descripción publicada en 1971 por Delgado Aragón ${ }^{15}$, en la que aparece de nuevo esta asociación entre la herranza y el kiwyu. La herranza de los campesinos de habla quechua de Carabaya (Puno), en la frontera entre Perú y Bolivia, incluía -al menos hace tres décadas-numerosas canciones y danzas alusivas a un ave llamada «kiyu». Al final de las celebraciones, cuando se guardaban los utensilios para marcar las bestias, Delgado observó «el repunto o danza del kiyu». En primer lugar, confirma que se trata de la misma ave o de una especie muy similar: "La concurrencia baila animadamente la danza del kiyu: se trata de imitar las costumbres de esta ave, semejante a la perdiz y que abunda en la región» (Delgado 1971: 195-196). La danza, como en el valle de Chancay también imita ciertas «costumbres» adjudicadas a las perdices. Se pueden entrever algunos movimientos:

«se agarran de la mano formando círculo; dentro del círculo penetra un hombre, el machu kiyu que con una voz gruesa, insistentemente grita: «Inlau, ar, ar, ar... inlau, ar, ar, arrr... inlau, arr, arr, arr». Los varones contestan: «Kiyu, kiuy, kiyu...». Las mujeres jubilosas, danzando de un lugar a otro, cantan una infinidad de versos... tratan de satirizarse mutuamente. Entonces, se entabla un contrapunto: cada vez, el repertorio aumenta» (Delgado 1971: 195-196).

En el valle de Chancay, los «vasallos» bailaban el kiwyu girando en círculo alrededor de la «bandera» sostenida por el «capitán». Cada uno sujetaba en sus manos un látigo, cuyo extremo opuesto era enredado en la «bandera». Como manecillas simultáneas de un mismo reloj, los «vasallos» debían girar en el mismo sentido.

Como sucedía con los vasallos de la herranza de Lima, también los hombres-perdices de Carabaya formaban un círculo. En el centro se encuentra el «machu kiyu». Machu significa antiguo, anciano, antepasado, y también tiene connotaciones de valiente, viril. La perdiz del centro debió haber sido, pues, la más antigua, la que lidera. En el valle de Chancay, quien está en medio del círculo es el «capitán», que no sólo lidera a los «vasallos», sino que también es el de mayor edad. En la descripción de Delgado Aragón esta distinción se expresa, además, por medio de la imitación de los gorjeos, que otra vez hacen pensar en un diálogo. La perdiz principal dice « ¡Inlau, ar, ar, ar! ¡Inlau, ar, ar, arrr! ¡Inlau, arr, arr, arr!». Las demás aves responden: «¡Kiyu, kiuy, kiyu!». La variante de Carabaya también alude a una suerte de competición, sobre todo cuando los participantes se «satirizan mutuamente» y «se entabla un contrapunto».

La escena siguiente se parece a lo observado en la fiesta del agua de Huaros. Se podría decir, incluso, que las descripciones de Delgado aluden también a la esfera del sacrificio:

pueblo del que proviene este breve testimonio, encontré un personaje llamado la «negra». Se trata de una representación muy similar, pero en versión femenina, pues el hombre está travestido. En otra fiesta del agua de la misma región de Canta (la del pueblo llamado Cullhuay), Borea (2004) encontró un personaje llamado «huaquero». Este protagonista recibe su nombre del recipiente adornado con flores (esta vez, de cerámica y con motivos prehispánicos) que llaman «huaco», y que debe llevar siempre lleno de alguna bebida alcohólica. En Cullhuay se cree que este personaje pasa una noche junto a la entidad que es dueña del agua (a la que llaman «la vieja»), haciéndole ofrendas y pidiéndole abundante agua y cultivos. Todo parece indicar, pues, que este personaje es una personificación muy cercana a los espíritus de los cerros.

15 Agradezco a Marie-France Souffez por llamar mi atención sobre este artículo. 
«De repente, en plena danza, se desbandan; los servicios van en persecución de los varones, hasta que llegan a coger uno; simulan matarlo, pelarlo y cocinarlo. Los otros llamándose, mediante silbidos que imitan a estas aves, se reúnen nuevamente y toman el kiyu-pelay, chicha tibia con azúcar» (Delgado 1971: 195-196).

Como en los dos casos observados directamente (en Canta y en Huaral), en Carabaya (Puno) los hombres-perdices interrumpen su danza para huir en todas direcciones. Los «asistentes» del anfitrión de la fiesta los persiguen. Atrapan a uno, lo matan, lo despluman y lo cocinan. Aunque en ambos casos el kiwyu es inevitablemente muerto, la cocción de Carabaya contrasta con la degollación de Huaros ${ }^{16}$.

Los hombres que no fueron atrapados siguen comportándose como perdices: se comunican «mediante silbidos que imitan a estas aves». Vueltos a reunir, los sobrevivientes liban «chicha», la cerveza de maíz común a muchas celebraciones en los Andes. Recordemos que, en Huaros, representa a la vez el arma defensiva de los kiwyus y su sangre sacrificada. Esta relación entre la chicha y el sacrificio parece confirmada por el nombre ritual de la bebida en Carabaya: kiyu-pelay. El primer término es el nombre del ave. Pela-y podría descomponerse en una raíz de origen español (del verbo pelar) junto con la marca del verbo infinitivo o del sustantivizador en quechua $(-y)$. Así, kiyu-pelay puede traducirse como desplumar, despellejar o desollar la perdiz. Esta alusión a la bebida tomada en Carabaya remite también a su papel en Huaros como la sangre del animal.

En conjunto, todos estos actos atribuidos a las perdices constituyen una suerte de legitimación de las danzas incluidas en el ritual ganadero. Esto es, como si la herranza tuviera una fuente de inspiración en la «naturaleza», o fuese el producto de una observación atenta de ella. Una naturaleza, por supuesto, particularmente «encantada», donde los animales poseen «rituales», esto es, los modelos sociales fundamentales de los hombres.

\section{Consideraciones finales. Las perdices y los jóvenes}

Comencemos con una coincidencia. En la mitología griega, Perdix (Пદ́p $\delta i \xi)$, el joven pupilo de Dédalo, es el autor de varios inventos. Entre otros, crea, inspirándose en ciertos animales como el pez y la serpiente, los instrumentos para trabajar la madera. $\mathrm{Su}$ éxito provoca los celos de su maestro, quien lo arroja desde lo alto del templo de Atenea. Pero ella, que favorece el ingenio, evita su caída transformándolo en una perdiz. Es por eso que este pájaro no hace su nido en los árboles ni vuela alto. Podría decirse que teme las alturas.

En la Grecia antigua, pues, un joven aprendiz, un mozo, también se transforma en perdiz, desplazándose hacia abajo, viniendo de lo alto. Además, provee de bienes culturales (de herramientas que redundan en beneficio de las actividades económicas) a su sociedad. Ahora bien, los jóvenes de la sierra de Lima que participan en la

\footnotetext{
16 Pareciera que en Carabaya se hubiese preferido atraer a la perdiz hacia el ámbito de lo humano (cuya metonimia es la cocina y sus artes), mientras que en Huaros han querido más bien entregarla como ofrenda a los espíritus de los cerros (cuya metáfora podría ser «la negra»). De todos modos, las razones de esta divergencia quedan por explicar.
} 
herranza, siguen un periplo no tan lejano al drama de Perdix: también son jóvenes aprendices, se convierten en aves cuando vienen de las alturas y, finalmente, cumplen un papel fundamental para la economía de su sociedad, «salvando» y reuniendo el ganado. ¿Pero que otras connotaciones y funciones debe cumplir Perdix en los Andes?

En los Andes centrales y del sur del Perú, los hombres atribuyen a las perdices unas «costumbres» que los hacen semejantes a ellos, y que, además, gustan de representar. ¿Por qué?

Lo primero que podemos constatar es que la imitación del «baile de las perdices» parece tener un mensaje distinto al de las otras parodias que los hombres hacen del comportamiento animal. En efecto, aquí no parece enfatizarse un predominio o una burla del mundo silvestre, como sucede cuando los ganaderos imitan a sus reses.

Recapitulemos. Los ritos ganaderos implican una distinción entre dos espacios, una distinción tan «imaginaria» como la danza de las perdices. Uno de ellos es la villa. Ella representa el mundo de los hombres. Asentada en el valle, es el centro de la vida social y económica y es el escenario de muchas fiestas que otorgan identidad al pueblo. El otro espacio son las «alturas», donde pasta y vive el ganado. El objetivo, digamos primordial de los ritos ganaderos, es eliminar el potencial aspecto «antisocial» (o más bien «asocial») que tiene la crianza del ganado. Esta «asocialidad» proviene, como se puede prever, de las «alturas», un espacio imprescindible para la ganadería, pero, al mismo tiempo, «peligroso», «ajeno» y casi contrario al mundo de los hombres. El peligro que la herranza quiere conjurar se deriva, además, del tiempo en que se celebra: agosto y su entorno son un tiempo en el que la tierra está abierta, hambrienta.

A consecuencia de estas concepciones sobre un cierto tiempo y un cierto espacio, la herranza necesita traer los rebaños de las «alturas» hasta el pueblo. Así, el ganado es transferido del dominio de los espíritus de los cerros al del pueblo. Los actores en juego son, pues, éste (el receptor), el espíritu de los cerros (el donante) y el ganado (el objeto donado) ${ }^{17}$.

Ahora bien, una de las estrategias que acompañan esta dinámica de uniones y disyunciones es la «contaminación de los comportamientos», es decir, la serie de animalizaciones y humanizaciones. En general, sabemos que el intercambio de papeles, entre animales y hombres, constituye un fenómeno recurrente en los rituales ganaderos andinos. ¿Pero cuáles son las actitudes que expresan estas contaminaciones? Encontramos dos:

- Una atracción por la animalidad. Los participantes del ritual parecen desear impregnarse de algunos de los atributos idealizados del ganado (la virilidad o la fertilidad).

- Un distanciamiento, en dos grados. En un primer grado, la herranza sirve también para hacer una parodia del comportamiento animal, mostrando con humor cuán impropia es tal parodia. Se resalta, pues, la necesidad de que los hombres se comporten como les corresponde. Ahora bien, en un segundo grado, cuando los animales son forzados a

17 El ritual parece operar algo más que una simple transmisión. Los rebaños son transformados de un «don recibido» en un «don ofrecido». Esta transformación se opera cuando los criadores hacen, al final de la herran$\mathrm{za}$, ofrendas a los espíritus de los cerros en las que incluyen «partes» de los animales (su pelambre, su sangre o trozos de sus orejas). La causa de esta transformación es que un don recibido simbolizaría la dependencia de la comunidad frente a los espíritus de los cerros, frente a la naturaleza. En cambio, un don ofrecido puede aludir a la alianza. 
adoptar los hábitos y la parafernalia de los hombres (celebrar un matrimonio, ser bautizados y usar adornos corporales), se opera una suerte de rechazo de la animalidad. Y se promueve, así, su redomesticación, llevando a un cierto extremo la lógica que trata de acercar a los animales al mundo de los hombres.

La atracción, a veces en forma de juego, es asumida sobre todo por los participantes más jóvenes del rito. La parodia y el rechazo (esto es, el distanciamiento), en cambio, son expresados por los ganaderos de mayor edad, que toman distancia frente a la imitación de la conducta animal e incluso obligan a los animales a asumir sus «costumbres». Creemos que esta distribución de actitudes por grupos de edad, ilustra las etapas del proceso de maduración de las personas. De ser el caso, la contaminación de los comportamientos (una de cuyas expresiones es la «danza de las perdices») concerniría a las perspectivas tanto sobre el mundo de los animales como sobre el mundo de los hombres. Así, la «danza de las perdices» mostraría bien cómo la herranza no sólo lidia con las distinciones ontológicas entre hombres y animales, sino también con aquellas que conciernen al ciclo vital de los hombres.

La expedición de los mozos a «las alturas», no puede sino intensificar su carácter «silvestre», propio de la fase del ciclo vital en que se encuentran. Esta suerte de radicalización concuerda con su apariencia animal cuando retornan al pueblo. En cierto modo, su de por sí débil humanidad ha menguado ya tanto que poco los distingue de las perdices de las alturas.

La imitación de un animal en la herranza depende siempre de las analogías, establecidas por la convención, entre las características de imitados e imitadores. Cada miembro de la sociedad asume una imitación distinta, según la etapa de su vida y la posición social adscrita a su ciclo vital. Así, los adultos se asocian al ganado cuando éstos se encuentran ya en el redil, donde se identifican los rebaños como su propiedad. En cambio, los jóvenes se asocian a la perdiz, un animal no domesticado pero con un momentáneo comportamiento cultural, durante el descenso del ganado, en el espacio liminal entre el pueblo y las alturas. La sociedad de los hombres sitúa la adolescencia en el borde de un círculo concéntrico, en cuyo centro se encuentran las características que definen la humanidad cabal. En los círculos intermedios se encuentran los jóvenes y niños, según su relación con aquellas características. Fuera del círculo se encuentra lo no-humano, incluyendo los animales. Ciertos animales, como las perdices, se sitúan en el borde externo de esa circunferencia, cercano a la adolescencia. La perdiz, pues, parece cumplir un papel similar al que Gary Urton encuentra que se da al oso en Pacariqtambo (Cuzco): metáfora animal usada para hablar de los jóvenes.

«They are the kind of animals that should exist so human society can differentiate itself from the 'society' of animals in nature. That is, ayllu society can define adolescence as its boundary within the variations of humankind, and it can define bears as its boundary at the point of contact between humans and animals. Therefore, ukuku dancers do not «symbolize» anything; rather, they are that thing. They are a combination of the one human thing (adolescents) and the one animal thing (bears) that best defines the boundary across which one must pass in order to be transformed into a mature human being: a member of an ayllu» (Urton 1985: 272). 
Como los mozos vueltos osos, los jóvenes actuando como kiwyus ilustran el punto de contacto entre lo humano y lo animal. Los danzantes no hacen más que jugar con esta ambigüedad. Evocan el límite que uno no debe cruzar, el punto del que uno debe alejarse si quiere convertirse en un ser humano maduro, en un miembro cabal de la sociedad de los hombres.

Antes de terminar, puede notarse que el animal en cuestión es aquel que, en el mundo silvestre, más se acerca a lo humano. De hecho, por medio de su «danza» los kiwyus representan una intromisión de la cultura (de un comportamiento ritualizado y jerarquizado) en la naturaleza (las alturas) en tanto metonimia de la sociedad. La danza de los kiwyus estaría introduciendo un aspecto crucial de la vida social (un rito) en el seno mismo de un mundo que la niega. La danza de las perdices y la herranza que la contiene son, pues, dos caras de una misma moneda. Si la danza de la perdiz constituye una intromisión de la cultura en la naturaleza, la herranza intenta arrebatar el ganado al mundo de la naturaleza y conducirlo al mundo de la cultura. En un caso, unos hombres «silvestres» (los jóvenes «vasallos») operan el cambio. En el otro, unos animales extrañamente «culturales» (los kiwyus) representan el tránsito. Ambos, la danza de las perdices y la herranza del ganado, pueden constituir metáforas idóneas del paso de un orden a otro.

El baile imaginado de la perdiz constituye una suerte de reflejo del ritual ganadero o, más precisamente, de sus objetivos fundamentales. Es como si los participantes de la herranza hubiesen imaginado un ritual animal sólo con el fin de reflejarse en él. Un ritual que deforma y ejemplifica como una caricatura la danza de los kiwyus (donde unos animales introducen la cultura en la naturaleza) e invierte los términos del ritual ganadero (donde los hombres introducen la naturaleza en la cultura), replicando, sin embargo, su mismo mensaje.

Si se lee, pues, el ritual ganadero como un comentario acerca de la persona, como una parábola sobre lo que es un hombre cabal, la danza de las perdices nos habla, entonces, de la maduración de los hombres. Esta interpretación no tiene por qué ser excluyente, de hecho la cuestión de la maduración de los jóvenes se vincula, a través de distintas analogías, con el drama de la domesticación y con los problemas de la emigración.

\section{Post-scriptum}

Después de entregado este texto a los editores, encontré una lectura de mucha utilidad para atisbar las posibilidades comparativas de este tema. En efecto, A. Gómez (2000) nos brinda una colección de referencias eruditas en torno a las creencias medievales sobre la perdiz en Europa. Así, por ejemplo, encontramos que, como el valle de Chancay, la «Historia natural» de Francisco Marcuello de 1617 y un «recetario» de Gilberto en la Biblioteca de Palacio de Madrid, asocian las perdices y sus huevos a la lujuria y el erotismo. Acercándonos a este mundo -algo que lamentablemente no es común en una antropología andina actualmente cerrada sobre si misma-, no dejan de llamar la atención (y a estudio) las similitudes y coincidencias entre ese mundo europeo y el de los Andes rurales de hoy. 


\section{Referencias bibliográficas}

AdelaAr, Willem F. H.

1982 Léxico del quechua de Pacaraos. Lima: Centro de Investigación de Lingüística Aplicada, Universidad Nacional Mayor de San Marcos.

AdelaAr, Willem y Peter Muysken

2007 The Languages of the Andes. Cambridge: Cambridge University Press.

BALDEÓn, Pedro

2001 Junín. Almanaque festivo. Lima: Organización para el Desarrollo Ambiental y Socio Ambiental (ODESA).

Benavides Estrada, Juan Augusto

s/f [¿1980?] La comunidad campesina de Huascoy, estructura económico-social y realidad educativa. Lima: Universo.

Borea, Giuliana

2004 «Tras los pasos del parián en el evento y en el tiempo. Imágenes y representaciones en la sierra de Lima». Anthropologica 22: 151-178. Lima.

Cerrón-Palomino, Rodolfo

1976 Diccionario quechua Junín-Huanca. Lima: Instituto de Estudios Peruanos - Ministerio de Educación.

Cieza de León, Pedro

1985 Crónica del Perú (segunda parte) [1871, edición póstuma]. Lima: Pontificia Universidad Católica del Perú.

Delgado Aragón, Julio

1971 «El señalakuy». Allpanchis Phuturinqa 3 (3): 185-197. Cuzco.

Gómez Moreno, Ángel

2000 «La perdiz en la literatura, el folklore y el arte». Cuadernos de Filología Italiana número extraordinario: 85-98. Madrid.

Gose, Peter

1994 Deathly Waters and Hungry Mountains. Agrarian Ritual and Class Formation in an Andean Town. Toronto: University of Toronto Press.

MurRA, John

1975 Formaciones económicas y politicas del mundo andino. Lima: Instituto de Estudios Peruanos.

2002 El mundo andino. Población, medio ambiente y economía. Lima: Pontificia Universidad Católica del Perú - Instituto de Estudios Peruanos.

PARKer, Gary y Amancio ChÁvez

1976 Diccionario quechua Ancash-Huailas. Lima: Instituto de Estudios Peruanos - Ministerio de Educación.

QuesADA, Félix

1976 Diccionario quechua Cajamarca-Cañaris. Lima: Instituto de Estudios Peruanos Ministerio de Educación.

Rivera ANDÍA, Juan Javier

2002 «Ritos agrícolas en el valle del Chancay (Lima). Testimonios sobre las celebracio- 
nes en torno a la limpieza de acequia recopilados cuarenta años después». Anthropologica 20: 309-332. Lima.

2003 La fiesta del ganado en el valle de Chancay (1962-2002). Religión y ritual en los Andes: etnografía, documentos inéditos e interpretación. Lima: Pontificia Universidad Católica del Perú.

SAntos Hurtado, Edwin

1999 La danza de los kivios. Lima.

Tschudi, Johann Jakob von

1849 Travels in Peru during the Years 1838-1842, on the Coast, in the Sierra, across the Cordilleras and the Andes, into the Primeval Forests. Nueva York: George P. Putman.

URTON, Gary

1985 «Animal Metaphors and the Life Cycle in an Andean Community», en Animal Myths and Metaphors in South America, Gary Urton, ed., pp. 251-284. Salt Lake City: University of Utah Press.

Vargas Salgado, Humberto

1990 «La comunidad campesina de Laraos y el rito de la champería». Anthropologica 8: 193-214. Lima. 